\title{
Are neutrophil/lymphocyte ratio and platelet/ lymphocyte ratio reliable parameters as prognostic indicators in malignant mesothelioma?
}

This article was published in the following Dove Press journal:

Therapeutics and Clinical Risk Management

22 April 2016

Number of times this article has been viewed

\author{
Seda Tural Onur' \\ Sinem Nedime Sokucu' \\ Levent Dalar ${ }^{2}$ \\ Sinem Iliaz' \\ Kaan Kara' \\ Songül Buyukkale ${ }^{3}$ \\ Sedat Altin' \\ 'Department of Chest Diseases, \\ Yedikule Chest Diseases and Thoracic \\ Surgery Training and Research \\ Hospital, ${ }^{2}$ Department of Pulmonary \\ Medicine, Faculty of Medicine, Istanbul \\ Bilim University, ${ }^{3}$ Department of \\ Thoracic Surgery, Yedikule Chest \\ Diseases and Thoracic Surgery \\ Training and Research Hospital, \\ Istanbul, Turkey
}

Background: Malignant mesothelioma (MM) is an aggressive asbestos-related pleural tumor. The incidence is increasing with intensive use of asbestos in developing countries. We need an easily accessible, inexpensive, and reliable method for determining the low survival time prognosis of this tumor. The aim of our study was to investigate the viability of neutrophil/ lymphocyte ratio (NLR) and platelet/lymphocyte ratio (PLR) as prognostic indicators in MM. Patients and methods: Thirty-six patients with MM, whose histopathologic diagnosis and follow-up were performed by our clinic and whose complete archive data were accessible, were included in this retrospective study. The patients' histopathologic disease types and stages, complete blood count parameters at diagnosis, and survival were recorded.

Results: Eighteen of the patients with MM were male and the remaining 18 of them were female; the average follow-up period was $24.83 \pm 3.61$ months. The PLR levels of the patients were statistically significant $(P<0.05)$. The NLR and PLR area under the receiver operating characteristic curve values were 0.559 and 0.749 , respectively $(P=0.631$ and $P=0.044$, respectively).

Conclusion: PLR was a significant prognostic indicator of MM at diagnosis on complete blood count parameters; however, NLR was not a significant prognostic indicator. A large number of prospective studies are needed to prove the reliability of the parameters.

Keywords: malignant mesothelioma, neutrophil/lymphocyte ratio, platelet/lymphocyte ratio, survival

\section{Introduction}

Malignant mesothelioma (MM) is associated with asbestos and erionite, which becomes trapped in serosal cavities of the body after exposure and is an aggressive neoplastic disease. ${ }^{1}$ The incidence of $\mathrm{MM}$ is increasing in many countries, including Turkey, due to increased industrial asbestos use and extensive environmental contact. $^{2,3}$ A mean latency period of 20-40 years can be seen after exposure, before the disease becomes apparent. ${ }^{4}$ Male predominancy is observed as age increases, and the disease is usually in its advanced stages at the time of diagnosis. ${ }^{4,5}$ The median survival rate is $7-24$ months but can change according to stage and therapy. ${ }^{6-8}$ The 5 -year survival is $<5 \% .{ }^{5}$ Combination therapies are often used because one therapy is insufficient. ${ }^{9}$

The European Organisation for Research and Treatment of Cancer (EORTC) and the Cancer and Leukemia Group B (CALGB) are prognostic scoring systems designed for patients with MM. ${ }^{10,11}$ In daily practice, these scoring systems cannot be used in patients with MM because they are too detailed and time consuming, which has been
Department of Chest Diseases, Yedikule Chest Diseases and Thoracic Surgery Training and Research Hospital,

Zeytinburnu, Istanbul 34760, Turkey

Tel +902I2 4090202

Fax +90 2125472233

Email sedatural@yahoo.com 
the subject of some studies. ${ }^{12,13}$ Prognostic assessment methods that are easy to use, inexpensive, and effective are needed for these patients.

Systemic inflammation parameters are increased in solid organ tumors and have been shown to have prognostic values in previous studies. ${ }^{14,15}$ Inflammation plays an important role in $\mathrm{MM}$ as the disease progresses, as it does in other malignancies. ${ }^{16}$

Neutrophils, lymphocytes, platelets, and mean platelet volume (MPV) are seen on the routine complete blood count (CBC). Neutrophil/lymphocyte ratio (NLR) is calculated by dividing the number of neutrophils by the number of lymphocytes, and the platelet/lymphocyte ratio (PLR) is similarly calculated, by dividing the number of platelets by the number of lymphocytes. NLR and PLR are global inflammation markers that have prognostic value in solid organ tumors that have been detected early. ${ }^{17-21}$ However, it is important to note that NLR can increase in many other nonmalignant conditions. ${ }^{22,23}$

In some previously performed studies, NLR and PLR's prognostic value was investigated in patients with MM. In our study, we aimed to prove the reliability of the $\mathrm{CBC}$ parameters NLR and PLR as prognostic indicators, which are inexpensive and easy for clinicians and comfortable for patients.

\section{Patients and methods \\ Patients}

The current study was performed from January 2014 through September 2014 in patients with histopathologic diagnosis of MM. We retrospectively examined the archive files of patients who had been histopathologically diagnosed as having MM after being investigated for exudative pleural fluid and had undergone parietal pleural biopsy by Cope needle or video-assisted thoracic surgery in our clinic and followed up monthly. Patients who had complete MM stages, histopathologic subtypes, and laboratory parameters were included in the study. The study conforms with the Code of Ethics of the World Medical Association (Declaration of Helsinki) printed in British Medical Journal (July 18, 1964). The approval for the study was given by the local ethics committee of Yedikule Chest Diseases and Thoracic Surgery Training and Research Hospital. All patients participating in the study gave written information consent.

The CBC taken at the time of diagnosis was used. The red blood cell distribution width (RDW), MPV, platelet distribution width, neutrophil, and platelet count were determined using an Abbott Cell-Dyn 3700 System (Abbott Laboratories,
Abbott Park, IL, USA); a differential count was included as part of the complete blood cell count. Serum biochemical parameters were measured using a Beckman Coulter AU2700 plus (Olympus Corporation, Tokyo, Japan).

\section{Statistical analysis}

For statistical analysis, Number Cruncher Statistical System 2007 and Power Analysis and Sample Size 2008 statistical software (IBM Corporation, Armonk, NY, USA) programs were used.

In this study, standard data assessment statistical methods (mean, SD, median, frequency, ratio, minimum, maximum) were used, and for abnormally distributed data, the quantitative two data group comparison Mann-Whitney $U$-test was used. Kaplan-Meier survival analysis was used for survival rates. Threshold levels under the curve (area under the curve) and a receiver operating characteristic (ROC) curve analysis was used for determination of the identifying properties and biochemical parameters of NLR and PLR. For ROC area under the curve comparison, the statistical package MedCalc Version 9.2.0.1 (MedCalc Software, Mariakerke, Belgium) was used. Significance was assessed at levels of $P<0.01$ and $P<0.05$.

\section{Results}

Thirty-six patients comprising 18 males (50\%) and 18 females $(50 \%)$ were analyzed. The age of patients ranged from 33 years to 89 years with a mean of $58.36 \pm 12.22$ years. The most frequent symptom reported by the patients was backache. Thirty-two of the patients $(88.8 \%)$ had a history staying in areas of endemic asbestosis in different regions of Turkey. Of the patients, $30.6 \%(n=11)$ were cigarette smokers and their cigarette usage mean was 35.82 \pm 28.03 and median was 30 packages/year. The demographic data of patients are shown in Table 1 . The mortality ratios and MM

Table I Distribution of descriptive characteristics

\begin{tabular}{ll}
\hline Characteristics & \\
\hline Age (years) & $33-89$ \\
Minimum-maximum & $58.36 \pm 12.22$ \\
Mean \pm SD & \\
Sex, $n(\%)$ & $18(50.0)$ \\
$\quad$ Female & $18(50.0)$ \\
Male & \\
Comorbidities, $n(\%)$ & $23(63.9)$ \\
Yes & $13(36.1)$ \\
No & \\
Smoking, $n(\%)$ & $25(69.4)$ \\
Yes & $11(30.6)$ \\
No &
\end{tabular}


Table 2 Distribution of disease characteristics

\begin{tabular}{lll}
\hline Disease characteristics & $\mathbf{n}$ & $\%$ \\
\hline Diagnosis & & \\
$\quad$ Biphasic & 5 & 13.9 \\
Epithelioid & 29 & 80.6 \\
Mixed & 1 & 2.8 \\
Sarcomatoid & 1 & 2.8 \\
Lymphadenopathy & & \\
N0 & 22 & 61.1 \\
NI & 6 & 16.7 \\
N2 & 7 & 19.4 \\
N3 & 1 & 2.8 \\
Mortality & & \\
Yes & 29 & 75.0 \\
No & 7 & 25.0 \\
Stage & & \\
I & 7 & 19.4 \\
2 & 4 & 11.1 \\
3 & 14 & 38.9 \\
4 & 11 & 30.6 \\
\hline
\end{tabular}

properties of patients are shown in Table 2. The laboratory data of patients are shown in Table 3. Of the 36 patients, seven are alive while 29 died. The mean survival time was $24.83 \pm 3.61$ months.

A significant difference was found between the mortality and mean age of the patients $(P<0.05)$; the patients who died were of significantly older age. There was no significant difference between sex and mortality $(P>0.05)$. Relative to mortality, NLR, RDW, and MPV levels showed no significant difference $(P>0.05$; Table 4$)$. The area under the ROC curve was 0.599 for NLR, whereas it was 0.749

Table 3 Distribution of laboratory findings

\begin{tabular}{lll}
\hline Laboratory findings & Min-Max & Mean \pm SD \\
\hline HTC (\%) & $27.2-52.4$ & $38.28 \pm 6.16$ \\
Hemoglobin $(\mathrm{g} / \mathrm{dL})$ & $9.1-17.6$ & $12.59 \pm 2.13$ \\
MCV (fL) & $65-94$ & $83.46 \pm 5.69$ \\
RDW (\%) & $11.7-21.5$ & $14.70 \pm 2.21$ \\
MPV (fL) & $6.47-10.1$ & $8.45 \pm 0.79$ \\
PDW (fL) & $11.5-19.8$ & $15.23 \pm 2.12$ \\
Platelets $\left(\mathrm{I} 0^{3} / \mu \mathrm{L}\right)$ & $135-714$ & $343.97 \pm 134.00$ \\
Lymphocytes $(\mathrm{IO} / \mu \mathrm{L})$ & $0.44-3.46$ & $1.77 \pm 0.71$ \\
Neutrophil $\left(\mathrm{I} 0^{3} / \mu \mathrm{L}\right)$ & $2.66-12.8$ & $6.42 \pm 2.70$ \\
NLR & $1.7-20.61$ & $4.78 \pm 4.50$ \\
PLR & $44.9-802.3$ & $225.5 \pm 134.5$ \\
LDH $(\mathrm{U} / \mathrm{L})$ & $100-419$ & $213.94 \pm 61.56$ \\
ALP $(\mathrm{U} / \mathrm{L})$ & $38-375$ & $94.76 \pm 56.13$ \\
CRP (mg/L) & $0.2-44$ & $7.50 \pm 10.20$ \\
\hline Abbreviations
\end{tabular}

Abbreviations: Min-Max, minimum-maximum; HTC, hematocrit; MCV, mean corpuscular volume; RDW, red blood cell distribution width; MPV, mean platelet volume; PDW, platelet distribution width; NLR, neutrophil/lymphocyte ratio; PLR, platelet/lymphocyte ratio; LDH, lactate dehydrogenase; ALP, alkaline phosphatase; CRP, C-reactive protein.
Table 4 Assessment of laboratory findings by mortality

\begin{tabular}{llll}
\hline $\begin{array}{l}\text { Laboratory } \\
\text { findings }\end{array}$ & $\begin{array}{l}\text { Mortality (-), } \\
\text { median } \pm \text { SD }\end{array}$ & $\begin{array}{l}\text { Mortality (+), } \\
\text { median } \pm \text { SD }\end{array}$ & P-value \\
\hline NLR & $4.55 \pm 4.44(2.85)$ & $12.43 \pm 22.04(3.86)$ & $0.443^{\mathrm{a}}$ \\
RDW (\%) & $14.47 \pm 2.08(14)$ & $15.40 \pm 2.55(15.1)$ & $0.36 \mathrm{I}^{\mathrm{a}}$ \\
MPV (fL) & $8.51 \pm 0.87(8.3)$ & $8.30 \pm 0.44(8.1)$ & $0.985^{\mathrm{a}}$ \\
PLR & $218.32 \pm \mid 3.45(190.49)$ & $247.04 \pm 140.62(219.73)$ & $0.622^{\mathrm{a}}$ \\
\hline
\end{tabular}

Notes: aMann-Whitney U-test.

Abbreviations: NLR, neutrophil/lymphocyte ratio; RDW, red blood cell distribution width; MPV, mean platelet volume; PLR, platelet/lymphocyte ratio.

for PLR. The ROC curves for NLR and PLR are shown in Figure 1.

\section{Discussion}

In previously performed studies, NLR and PLR ratios were shown to be prognostic indicators for coronary heart disease, chronic kidney disease, granulomatous disease, chronic obstructive pulmonary disease, and cancer. ${ }^{22-26}$ Rassouli et al investigated prognostic value of head and neck squamous cell carcinoma in 235 patients and found that the NLR/PLR combination was at least as good as tumor-node-metastasis staging in predicting survival. They also stated that PLR is an independent predictor of mortality and NLR is an independent predictor of recurrence in head and neck squamous cell carcinoma. ${ }^{27}$ Our study has shown the importance of these parameters, which have shown benefits in the diagnosis of various diseases in $\mathrm{MM}$.

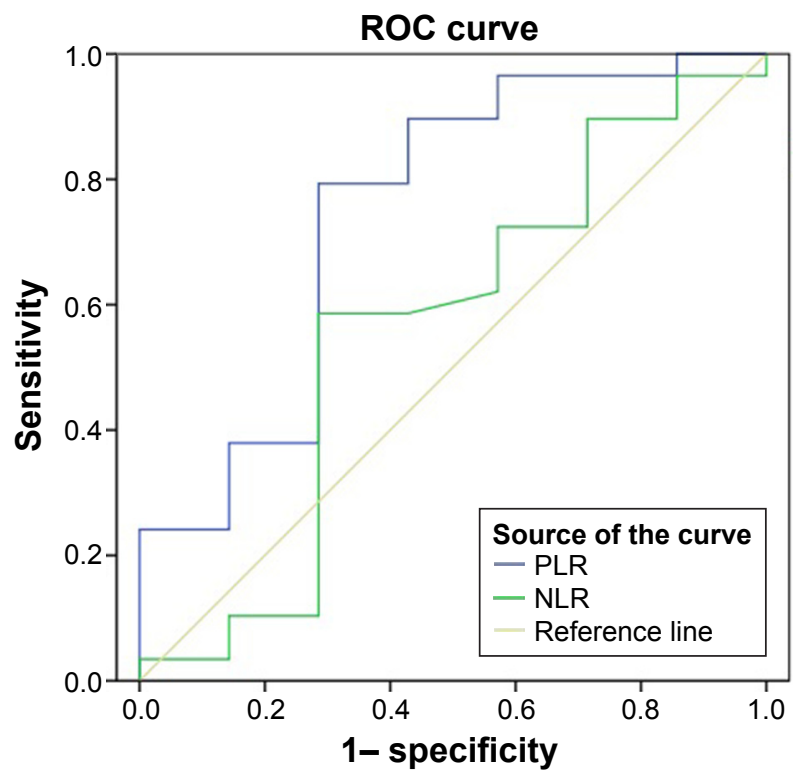

Figure I ROC curves of PLR and NLR.

Note: Diagonal segments are produced by ties.

Abbreviations: ROC, receiver operating characteristic; PLR, platelet/lymphocyte ratio; NLR, neutrophil/lymphocyte ratio. 
In industrialized countries, asbestos exposure is observed mostly in men, primarily associated with industrial use. Since the use of asbestos was restricted in 2005, the frequency of $\mathrm{MM}$ is expected to decrease over the years. The large number of environmental exposure in rural areas and industrial use in developing countries, such as Turkey, has led to more exposure to asbestos and erionite. The incidence of $\mathrm{MM}$ in countries with environmental exposure to asbestos is found to be equal between women and men. ${ }^{28,29}$ In the literature, the mean age of patients with MM was similar in studies that were performed in Turkey. ${ }^{30}$ In our study, the male to female ratio is equal. As demonstrated by our study, due to the high environmental exposure, MM can be seen at young ages like in our country.

The association of inflammation with neutrophil and platelet was investigated in cancer. CBC parameters were shown to be predictive and prognostic in most cancer types. ${ }^{17,19,27}$ In a study performed by Cihan et al that included 50 cases, white blood cell $<8,000$, platelet $<300,000$, and low NLR $(<5)$ and PLR $(<190)$ were identified to be good prognostic factors. ${ }^{31}$ Again from Turkey, another study performed by Abakay et al in a large population stated that when RDW is $\geq 20 \%$ and NLR $\geq 3$, MM prognosis was worse and these parameters could be used as a prognostic indicator. ${ }^{30}$ Kao et al identified that an NLR value of $>5$ was a worse prognostic factor in MM patients who were undergoing systemic treatment. ${ }^{20}$ In a retrospective study performed in 274 patients, at the time of diagnosis of MM, NLR was not identified as a prognostic factor. ${ }^{32}$ In our study, NLR calculated by full blood count parameters at the time of diagnosis was not found to be significant. The reason for this insignificancy can be because of our small sample size and different cutoff values for NLR. However, PLR was significant. The cutoff value for PLR is 158 . When PLR was $>150$ in previously performed studies, it was a prognostic factor for increased mortality in colorectal and pancreas cancer. ${ }^{33,34}$ In the only study that investigated the prognostic value of PLR score in patients with MM, low NLR and PLR scores and disease survey were not found to be statistically significant. ${ }^{31}$

White blood cell, neutrophil, lymphocyte, and NLR are systemic inflammation markers. Inflammation plays a role from diagnosis to the advanced stages of cancer. ${ }^{35,36}$ The severity of this inflammation can be an identifying factor for prognosis.

Although there is a known association between inflammatory markers and disease stage, it can be concluded that one-time NLR at the time of diagnosis is not an indicator for antitumoral immunity response..$^{33}$ One of the many reasons is that while lymphocytes have many phenotypes and various functions, the neutrophil count, the other parameter of NLR, increases in all acute inflammatory conditions but decreases under physiologic stress conditions. NLR is affected by many factors, and its dependency to antitumor inflammation and other factors decreases its significance. ${ }^{33}$

On the other hand, it is known that platelets also have an important role in inflammation and have prognostic importance in themselves. ${ }^{37}$ For this reason, it is not unexpected that the ratio of PLR has a prognostic value in MM. Cytokines are an important component of the inflammatory process, and their synthesis can induce changes to neutrophils, lymphocytes, and platelets. In addition, neutrophils, lymphocytes, and platelets all separately, positively, or negatively, play a role in tumor growth regulation. ${ }^{37}$ The neutrophil infiltration of tumor reduces the tumor growth. ${ }^{38}$ A previous study has shown that metastatic potential was inhibited and changed with a platelet count reduction. ${ }^{39}$

The limitations of our study could include the cell count because it was performed retrospectively. There were a few patients with comprehensive data, and these patients were not randomized to their treatment and their treatment protocols were not included in the study. Instead of ratios with one-time $\mathrm{CBC}$, a prospective study with ratios of different stages of disease could prove the reliability of these parameters. This could not be done in this study because of its retrospective nature, and it could also be evaluated as a limitation. Another limitation of our study is that our center is a diagnostic center only, and most of the patients were referred to other centers to be treated. Also, we do not have our patients' EORTC and CALGB stages and their treatment.

\section{Conclusion}

Considering the different studies in the literature, the prognostic situation of either the NLR or PLR scores remains controversial. For this reason, although these markers are easy to use and are inexpensive methods, it is too early to replace multiple prognostic survey indicators such as EORTC and CALGB.

We designed this study because of the fact that it would be beneficial for the survival of markers that can be used at the beginning of the diagnosis of MM, which has high mortality rate. However, as shown in our study, PLR score has a prognostic value in MM, and large-scale prospective studies are needed. In our study, a full blood count parameter PLR at the time of diagnosis was found to be a statistically significant prognostic indicator in MM. NLR is difficult to 
use in daily practice which affected other conditions. The NLR ratio was not found to be statistically significant as a prognostic indicator. The prognostic significance of PLR in MM seems to be promising for clinical use because it is inexpensive and easy to use.

\section{Acknowledgments}

The authors thank David Chapman for English-language editing. The manuscript was presented at the 18th Thorax Congress, Turkish Thoracic Society, Antalya, Turkey, as an oral presentation on April 1-5, 2015. The manuscript was also presented at the ERS Amsterdam 2015 International Congress, European Respiratory Society, Amsterdam, the Netherlands, as thematic poster on September 26-30, 2015, and the abstract was published in the European Respiratory Journal.

\section{Disclosure}

The authors report no conflicts of interest in this work.

\section{References}

1. Kao SC, Reid G, Lee K, Vardy J, Clarke S, van Zandwijk N. Malignant mesothelioma. Intern Med J. 2010;40:742-750.

2. Hodgson JT, McElvenny DM, Darnton AJ, Price MJ, Peto J. The expected burden of mesothelioma mortality in Great Britain from 2002 to 2050. Br J Cancer. 2005;92(3):587-593.

3. Antman KH. Natural history and epidemiology of malignant mesothelioma. Chest. 1993;103(4 suppl):373S-376S.

4. Antman K, Shemin R, Ryan L, et al. Malignant mesothelioma: prognostic variables in a registry of 180 patients, the Dana-Farber Cancer Institute and Brigham and Women's Hospital experience over two decades, 1965-1985. J Clin Oncol. 1988;6:147-153.

5. Ibrahim N, Abou-Elela E, Darwish D. Survival of mesothelioma in a palliative medical care unit in Egypt. Asian Pac J Cancer Prev. 2013;14: 739-742.

6. Vogelzang NJ, Rusthoven JJ, Symanowski J, et al. Phase III study of pemetrexed in combination with cisplatin versus cisplatin alone in patients with malignant pleural mesothelioma. J Clin Oncol. 2003;21: 2636-2644.

7. Weder W, Stahel RA, Bernhard J, et al. Multicenter trial of neo-adjuvant chemotherapy followed by extrapleural pneumonectomy in malignant pleural mesothelioma. Ann Oncol. 2007;18:1196-1202.

8. Spirtas R, Connelly RR, Tucker MA. Survival patterns for malignant mesothelioma: the seer experience. Int J Cancer. 1988;41:525-530.

9. Stahel RA, Weder W, Lievens Y, Felip E, ESMO Guidelines Working Group. Malignant pleural mesothelioma: ESMO clinical practice guidelines for diagnosis, treatment and follow-up. Ann Oncol. 2010;21: 126-128.

10. Curran D, Sahmoud T, Therasse P, van Meerbeeck J, Postmus PE, Giaccone G. Prognostic factors in patients with pleural mesothelioma: the European Organization for Research and Treatment of Cancer experience. J Clin Oncol. 1998;16:145-152.

11. Herndon JE, Green MR, Chahinian AP, Corson JM, Suzuki Y, Vogelzang NJ. Factors predictive of survival among 337 patients with mesothelioma treated between 1984 and 1994 by the Cancer and Leukemia Group B. Chest. 1998;113:723-731.

12. Edwards JG, Abrams KR, Leverment JN, Spyt TJ, Waller DA, O’Byrne KJ. Prognostic factors for malignant mesothelioma in 142 patients: validation of CALBG and EORTC prognostic scoring systems. Thorax. 2000;55:731-735.
13. Steele JP. Prognostic factors in mesothelioma. Semin Oncol. 2002;29:36-40.

14. Zhang L, Conejo-Garcia JR, Katsaros D, et al. Intratumoral T cells, recurrence, and survival in epithelial ovarian cancer. $N$ Engl J Med. 2003;348:203-213.

15. Al-Shibli KI, Donnem T, Al-Saad S, Persson M, Bremnes RM, Busund LT. Prognostic effect of epithelial and stromal lymphocyte infiltration in non-small cell lung cancer. Clin Cancer Res. 2008;14: 5220-5227.

16. Hillegass JM, Shukla A, Lathrop SA, et al. Inflammation precedes the development of human malignant mesotheliomas in a SCID mouse xenograft model. Ann N Y Acad Sci. 2010;1203:7-14.

17. Absenger G, Szkandera J, Pichler M, et al. A derived neutrophil to lymphocyte ratio predicts clinical outcome in stage II and III colon cancer patients. Br J Cancer. 2013;109:395-400.

18. Keskin S, Güler T, Kalkan H, Keskin Z, Ödev K. Pulmonary embolism and hematologic outcome in cancer patients initiating chemotherapy. Indian J Cancer. 2014;51:303-305.

19. Jafri SH, Shi R, Mills G. Advanced lung cancer inflammation index (ALI) at diagnosis is a prognostic marker in patients with metastatic non-small cell lung cancer (NSCLC): a retrospective review. $B M C$ Cancer. 2013;13:158.

20. Kao SC, Pavlakis N, Harvie R, et al. High blood neutrophil-to-lymphocyte ratio is an indicator of poor prognosis in malignant mesothelioma patients undergoing systemic therapy. Clin Cancer Res. 2010;16: 5805-5813.

21. Kao SC, Vardy J, Chatfield M, et al. Validation of prognostic factors in malignant pleural mesothelioma: a retrospective analysis of data from patients seeking compensation from the New South Wales Dust Diseases Board. Clin Lung Cancer. 2013;14:70-77.

22. Turkmen K, Erdur FM, Ozcicek F, et al. Platelet-to-lymphocyte ratio better predicts inflammation than neutrophil-to-lymphocyte ratio in end-stage renal disease patients. Hemodial Int. 2013;17:391-396.

23. Shah N, Parikh V, Patel N, et al. Neutrophil lymphocyte ratio significantly improves the Framingham risk score in prediction of coronary heart disease mortality: insights from the National Health and Nutrition Examination Survey-III. Int J Cardiol. 2014;171:390-397.

24. Kos FT, Hocazade C, Kos M, et al. Assessment of prognostic value of "neutrophil to lymphocyte ratio" and "prognostic nutritional index" as a sytemic inflammatory marker in non-small cell lung cancer. Asian Pac J Cancer Prev. 2015;16:3997-4002.

25. Günay E, Sarınç Ulaşlı S, Akar O, et al. Neutrophil-to-lymphocyte ratio in chronic obstructive pulmonary disease: a retrospective study. Inflammation. 2014;37:374-380.

26. Iliaz S, Iliaz R, Ortakoylu G, Bahadir A, Bagci BA, Caglar E. Value of neutrophil/lymphocyte ratio in the differential diagnosis of sarcoidosis and tuberculosis. Ann Thorac Med. 2014;9:232-235.

27. Rassouli A, Saliba J, Castano R, Hier M, Zeitouni AG. Systemic inflammatory markers as independent prognosticators of head and neck squamous cell carcinoma. Head Neck. 2015;37:103-110.

28. Senyiğit A, Bayram H, Babayiğit C, et al. Malignant pleural mesothelioma caused by environmental exposure to asbestos in the Southeast of Turkey: CT findings in 117 patients. Respiration. 2000;67: $615-622$.

29. Tanrikulu AC, Abakay A, Kaplan MA, et al. A clinical, radiographic and laboratory evaluation of prognostic factors in 363 patients with malignant pleural mesothelioma. Respiration. 2010;80:480-487.

30. Abakay O, Tanrikulu AC, Palanci Y, Abakay A. The value of inflammatory parameters in the prognosis of malignant mesothelioma. $J$ Int Med Res. 2014;42:554-565.

31. Cihan YB, Ozturk A, Mutlu H. Relationship between prognosis and neutrophil: lymphocyte and platelet:lymphocyte ratios in patients with malignant pleural mesotheliomas. Asian Pac J Cancer Prev. 2014;15:2061-2067.

32. Meniawy TM, Creaney J, Lake RA, Nowak AK. Existing models, but not neutrophil-to-lymphocyte ratio, are prognostic in malignant mesothelioma. Br J Cancer. 2013;109:1813-1820. 
33. Kishi Y, Kopetz S, Chun YS, Palavecino M, Abdalla EK, Vauthey JN. Blood neutrophil-to-lymphocyte ratio predicts survival in patients with colorectal liver metastases treated with systemic chemotherapy. Ann Surg Oncol. 2009;16:614-622.

34. Smith RA, Bosonnet L, Raraty M, et al. Preoperative platelet-lymphocyte ratio is an independent significant prognostic marker in resected pancreatic ductal adenocarcinoma. Am J Surg. 2009; 197:466-470.

35. Klinger MH, Jelkmann W. Role of blood platelets in infection and inflammation. J Interferon Cytokine Res. 2002;22:913-922.

36. Prete A, Allavena P, Santoro G, Fumarulo R, Corsi MM, Mantovani A. Molecular pathways in cancer-related inflammation. Biochem Med (Zagreb). 2011;21:264-275.
37. Germano G, Allavena P, Mantovani A. Cytokines as a key component of cancer-related inflammation. Cytokine. 2008;43:374-379.

38. Peng HH, Liang S, Henderson AJ, Dong C. Regulation of interleukin-8 expression in melanomastimulated neutrophil inflammatory response. Exp Cell Res. 2007;313:551-559.

39. Philippe C, Philippe B, Fouqueray B, Perez J, Lebret M, Baud L. Protection from tumor necrosis factor-mediated cytolysis by platelets. Am J Pathol. 1993;143:1713-1723.

\section{Publish your work in this journal}

Therapeutics and Clinical Risk Management is an international, peerreviewed journal of clinical therapeutics and risk management, focusing on concise rapid reporting of clinical studies in all therapeutic areas, outcomes, safety, and programs for the effective, safe, and sustained use of medicines. This journal is indexed on PubMed Central, CAS,
EMBase, Scopus and the Elsevier Bibliographic databases. The manuscript management system is completely online and includes a very quick and fair peer-review system, which is all easy to use. Visit http://www.dovepress.com/testimonials.php to read real quotes from published authors.

Submit your manuscript here: http://www.dovepress.com/therapeutics-and-clinical-risk-management-journal 